\title{
LA NOTIFICACIÓN JUDICIAL A UN ESTADO EXTRANJERO
}

\section{SERVICE ABROAD OF JUDICIAL DOCUMENTS TO A FOREIGN STATE}

\author{
Miguel Gómez Jene \\ Catedrático de Derecho Internacional Privado \\ UNED \\ ORCID ID: 0000-0002-4916-5119
}

Recibido: 28.06.2021 / Aceptado: 16.07.2021

DOI: https://doi.org/10.20318/cdt.2021.6289

\begin{abstract}
Resumen: Análisis del complejo marco normativo aplicable a la notificación de un Estado extranjero demandado ante un órgano judicial español y propuesta de interpretación.

Palabras clave: Notificación. Estado extranjero.

Abstract: Analysis of the complex regulatory framework applicable to the service abroad to a defendant foreign State before a Spanish court and proposal for interpretation.

Keywords: Service abroad. Foreign State.

Sumario: I. Introducción. II. El Reglamento europeo en materia de notificación: aplicación a comunicaciones dirigidas a Estados miembros de la UE. III. El marco jurídico de fuente interna: remisión al Convenio de Viena sobre Relaciones Diplomáticas de 18 de abril de 1961. IV. A modo de conclusión.
\end{abstract}

\section{Introducción}

1. El marco legal aplicable a la notificación de un Estado extranjero demandado ante tribunales españoles es complejo y aparentemente contradictorio. Junto con disposiciones convencionales (recogidas en distintos textos internacionales), la notificación a Estados extranjeros también tiene una regulación expresa en dos disposiciones de nuestro ordenamiento jurídico de fuente interna: el artículo 27 de la Ley de Cooperación Jurídica Internacional (LCJI) y el artículo 54 de Ley Orgánica sobre Privilegios e Inmunidades de los Estados Extranjeros (LOPI). Además, en los supuestos intraeuropeos (el Estado extranjero demandado es un Estado miembro de la UE), debe tenerse en cuenta también la posible aplicación del Reglamento de notificaciones refundido ${ }^{1}$.

2. Determinar el orden de aplicación de las normas potencialmente aplicables es el objeto de este estudio; y la oportunidad del mismo deriva del hecho de que la Asesoría Jurídica Internacional (AJI) del Ministerio de Asuntos Exteriores, Unión Europea y Cooperación (en adelante, Ministerio de

\footnotetext{
${ }^{1}$ Reglamento (UE) 2020/1784 del Parlamento Europeo y del Consejo de 25 de noviembre de 2020 relativo a la notificación y traslado en los Estados miembros de documentos judiciales y extrajudiciales en materia civil o mercantil («notificación y traslado de documentos») (Reglamento de notificación refundido).
} 
Asuntos Exteriores o MAEX) ha interpretado recientemente dicho marco legal de una forma, a mi juicio, cuestionable. Dicha interpretación se ha hecho por petición del TSJ de Madrid en el contexto de un procedimiento de auxilio a un arbitraje internacional.

3. Para estudiar la cuestión planteada, a continuación procederé a citar e interpretar las normas potencialmente aplicables a esta cuestión. Para ello empezaré haciendo una breve referencia a la aplicación del Reglamento de notificaciones refundido (de posible aplicación a supuestos intraeuropeos) en este tipo de supuestos. Posteriormente, analizaré el marco jurídico aplicable a los supuestos extraeuropeos (el Estado extranjero demandado no es un Estado miembro de la UE), y finalizaré con una breve conclusión que avanzo ahora de forma breve: los distintos cauces legales previstos en nuestro ordenamiento de fuente interna evitan la comunicación directa del tribunal del foro con el Estado demandado (preservando así su posible inmunidad) y garantizan los derechos de defensa del mismo. Por tanto, y sin perjuicio de las circunstancias de cada supuesto concreto (existencia o no de misiones diplomáticas en España o en el Estado extranjero), entiendo que practicar la notificación por cualquiera de los cauces previstos, sin orden de jerarquía, debe ser posible. De tal forma, además, que en un contexto de nulidad de actuaciones, el hecho de que el MAEX utilice una u otra vía no debiera tener la más mínima relevancia. No en vano, es el mismo MAEX -y no el órgano judicial- quien lleva a cabo esa notificación.

\section{EI Reglamento europeo en materia de notificación: aplicación a comunicaciones dirigidas a Estados miembros de la UE}

4. El artículo 1.1 del Reglamento de notificaciones refundido establece:

1. El presente Reglamento se aplica a la notificación y el traslado transfronterizos de documentos judiciales y extrajudiciales en materia civil y mercantil. No se aplica, en particular, en materia fiscal, aduanera o administrativa, o a la responsabilidad de un Estado miembro por acciones u omisiones en el ejercicio de su autoridad (acta iure imperii).

5. Como puede apreciarse, este instrumento excluye de su ámbito de aplicación la responsabilidad del Estado por acciones u omisiones en el ejercicio de su autoridad ("acta iure imperii"). Sin embargo, debe recordarse que la jurisprudencia del TJUE en interpretación del artículo 1 del Reglamento de notificaciones ${ }^{2}$ ha considerado que las notificaciones de demandas interpuestas por particulares tenedores de deuda pública contra un Estado están incluidas en su ámbito de aplicación ${ }^{3}$. Esta interpretación amplia obliga, por tanto, a analizar el alcance de la aplicación de este Reglamento a supuestos en los que el Estado extranjero demandado ante un tribunal español sea un Estado miembro de la UE.

6. A los efectos que ahora importan, debe tenerse en cuenta el alcance de las expresiones "civil y mercantil" y "acta iure imperii" que recoge el citado precepto, al objeto de concretar si las normas de fuente interna pueden quedar o no desplazadas por la aplicación de este instrumento. Y es que, si se entiende que el alcance de la expresión "materia civil y mercantil" debe ser amplia y que el alcance de la expresión "acta iure imperii" debe ser restringida, muchos pueden ser los supuestos en los que la notificación al Estado extranjero demandado deba hacerse por el cauce o cauces que este Reglamento prevé; y no por las disposiciones previstas en el ordenamiento de fuente interna.

7. A este respecto, cabe apuntar, con carácter preliminar, que la interpretación que el TJUE ha hecho de las expresiones citadas en interpretación del Reglamento Bruselas I refundido es extrapolable al

\footnotetext{
${ }^{2}$ Reglamento (CE) 1393/2007 del Parlamento Europeo y del Consejo de 13 de noviembre de 2007 relativo a la notificación y traslado en los Estados miembros de documentos judiciales y extrajudiciales en materia civil o mercantil.

${ }^{3}$ STJUE, 11.6.2015, C-226/13 y acumulados, Helenische Republik. ECLI:EU:C:2015:383.
} 
ámbito del Reglamento de notificaciones refundido ${ }^{4}$. Y así, es de destacar que el TJUE ha interpretado el alcance de la expresión "civil y mercantil" de forma amplia y autónoma. Es decir, la noción en cuestión no debe definirse por remisión al ordenamiento de un Estado concreto, sino atendiendo tanto a los objetivos y el sistema del Reglamento, como a los principios generales que se desprenden del conjunto de los sistemas de Derecho nacionales. A partir de aquí, para determinar si una materia es civil y mercantil es preciso examinar: (i) los rasgos que caracterizan la naturaleza de las relaciones jurídicas entre las partes del litigio; o (ii) el objeto del litigio. Ambas circunstancias no tienen por qué darse de forma cumulativa. A la luz de este examen puede concluirse que están excluidos del ámbito de aplicación tanto del Reglamento Bruselas I refundido como del Reglamento de notificación los litigios derivados de contratos con el Estado sometidos a un régimen jurídico público, los litigios derivados de un procedimiento de expropiación forzosa y los litigios de cobro de aranceles notariales (el notario como autoridad pública) ${ }^{6}$.

8. El papel que asume la autoridad pública que actúa en el litigio es también determinante a la hora de concretar si el supuesto está o no incluido en el ámbito de aplicación del Reglamento (excepción "acta iure imperii"). Si actúa en el ejercicio del poder público, el litigio queda excluido del ámbito de aplicación del Reglamento 7 . Por tanto, para determinar si el Reglamento de notificación refundido es o no aplicable a un supuesto en el que un Estado sea parte -lo que supondría la inaplicación de las disposiciones de fuente interna- debe determinarse si la participación del Estado en la relación jurídica controvertida se caracteriza "de modo patente por constituir una manifestación de la potestad pública, por corresponder al ejercicio de facultades exorbitantes en relación con las normas aplicables en las relaciones entre particulares". O dicho de otro modo: "la manifestación de prerrogativas de poder público por una de las partes en el litigio, en virtud de su ejercicio de poderes exorbitantes en relación con las normas aplicables a las relaciones entre particulares, excluye tal litigio del concepto de materia civil y mercantil"".

9. Desde esta perspectiva requiere especial atención la sentencia del TJUE en el asunto Helelenische Republik ${ }^{10}$.

En el supuesto, una serie de bonistas alemanes adquirieron obligaciones emitidas por el Estado griego. A resultas de un cambio legislativo, el Estado griego ofertó un canje -por valor nominal inferiorde obligaciones ya emitidas por obligaciones de nueva emisión. Este cambio de obligaciones exigía la aceptación expresa de los acreedores privados. No obstante, el gobierno griego procedió al canje incluso frente a bonistas que no consintieron la oferta. En consecuencia, ciertos bonistas ejercitaron acciones por incumplimiento de obligaciones contractuales. Y fue en el marco del procedimiento de notificación al Estado griego donde se suscitó la cuestión relativa a la aplicación del Reglamento de notificación.

10. El TJUE entendió que tal supuesto estaba incluido en el ámbito de aplicación del Reglamento de notificación y, en consecuencia, que el Estado griego debía ser notificado por los cauces previstos en el mismo. En concreto, partiendo de la base de que la "finalidad de dicho Reglamento es mejorar y acelerar la transmisión de los documentos judiciales y extrajudiciales, a fin de garantizar el buen funcionamiento del mercado interior", "que la posibilidad de rechazar la notificación o el traslado de los documentos se limita a situaciones excepcionales" y que las solicitudes sólo deben devolverse cuando estén "manifiestamente fuera del ámbito de aplicación del Reglamento"11, el TJUE entendió que la emisión de obligaciones no

\footnotetext{
${ }^{4}$ Sobre el alcance de ambas expresiones - detenidamente- en el contexto del Reglamento Bruselas I refundido, vid. M. GóMez Jene, “Artículo 1", en: Pérez LLorCa, Comentario al Reglamento 1215/2012 relativo a la competencia judicial, el reconocimiento y la ejecución de resoluciones judiciales en materia civil y mercantil, Aranzadi, Pamplona, 2016, pp. 59-65.

${ }_{5}^{5}$ Entre otras, STJUE, 10.9.2009, C-292/08, German Graphics, ECLI:EU:C:2009:544.

6 Ya en este sentido, M. Virgós Soriano / F. J. Garcimartín Alférez., Derecho procesal civil internacional. Litigación internacional, Madrid, Civitas, 2007, pp. 98-99.

7 Vid. como uno de los referentes más recientes, la STJUE, 25.3.2021, C-307/19, Obala, ECLI:EU:C:2021:236.

8 STJUE, 15.2.2007, C-295/05, Lechouritou, ECLI:EU:C:2007:227 y sentencia citada en la nota núm. 3.

9 STJUE, 28.4.2009, C-420/07, Apostolides, ECLI:EU:C:2009:271.

10 Vid. supra nota 3.

11 Vid. marginales 40 y 41 de la sentencia.
} 
presupone necesariamente el ejercicio de facultades exorbitantes en relación con las normas aplicables en las relaciones entre particulares, pues "no cabe excluir que una persona jurídica de Derecho privado pueda acudir al mercado para financiarse, concretamente mediante la emisión de obligaciones" 12 . Del mismo modo, tampoco procede hablar de un supuesto iure imperii si no resulta manifiesto que las condiciones financieras de los títulos controvertidos son fijadas unilateralmente por el Estado en cuestión. En el caso, el Tribunal consideró que no resultaba manifiesto que la adopción de una Ley hubiera producido directa e inmediatamente modificaciones en cuanto a las condiciones financieras de los títulos controvertidos.

11. El razonamiento así hecho por el TJUE es particularmente clarificador sobre la interpretación que debe hacerse del Reglamento de notificación a la hora de evaluar las circunstancias del supuesto y, en consecuencia, considerar o no incluido el mismo en su ámbito de aplicación material.

\section{El marco jurídico de fuente interna: remisión al Convenio de Viena sobre Relaciones Diplo- máticas de 18 de abril de 1961.}

12. En defecto de aplicación del Reglamento de notificaciones o en supuestos extraeuropeos será de aplicación, en primer lugar, el Derecho convencional ratificado por España y, subsidiariamente, las normas del ordenamiento jurídico de fuente interna que regulan este particular supuesto: como hemos adelantado ya, el artículo 27.1 LCJI y el artículo 54.1 LOPI. A continuación recogemos el tenor de los preceptos aplicables, para mejor compresión de las interpretaciones que el marco en cuestión plantea.

Artículos 3.1 y 41.2 del Convenio de Viena sobre Relaciones Diplomáticas de 18 de abril de 1961.

3.1. Las funciones de una misión diplomática consisten principalmente en:

a) Representar al Estado acreditante ante el Estado receptor.

41.2. Todos los asuntos oficiales de que la misión esté encargada por el Estado acreditante han de ser tratados con el Ministerio de Relaciones Exteriores del Estado receptor por conducto de él o con el Ministerio que se haya convenido.

Artículo 27 LCJI. Emplazamientos y comunicaciones judiciales dirigidos a Estados extranjeros.

1. Los emplazamientos, citaciones, requerimientos y cualesquiera otros actos de comunicación judicial dirigidos a Estados extranjeros se realizarán por vía diplomática a través del Ministerio de Asuntos Exteriores y de Cooperación, debiendo comunicarse por nota verbal y de conformidad con lo establecido en la Convención de Viena sobre Relaciones Diplomáticas de 18 de abril de 1961.

Artículo 54 LOPI. Procedimiento de comunicación entre el Ministerio de Asuntos Exteriores y de Cooperación y los órganos jurisdiccionales españoles

1. El Ministerio de Asuntos Exteriores y de Cooperación remitirá el emplazamiento o la notificación del órgano jurisdiccional a la misión diplomática o a la representación permanente española correspondiente, a los efectos de su traslado al Ministerio de Asuntos Exteriores del Estado extranjero o al órgano competente de la organización internacional.

Artículo 22.1 de la Convención NU sobre las Inmunidades Jurisdiccionales de los Estados y de sus Bienes (no en vigor).Notificación de la demanda

1. La notificación de la demanda u otro documento por el que se incoe un proceso contra un Estado se practicará:

${ }^{12}$ Marginal 55 de la sentencia. 
a) de conformidad con cualquier convenio internacional aplicable que obligue al Estado del foro y al Estado interesado; o

b) de conformidad con cualquier arreglo especial de notificación entre el demandante y el Estado interesado, si no lo prohibe la legislación del Estado del foro; o

c) a falta de tal convenio o arreglo especial:

i) transmitiéndola por vía diplomática al Ministerio de Relaciones Exteriores del Estado interesado; o

ii) por cualquier otro medio aceptado por el Estado interesado, si no lo prohíbe la legislación del Estado del foro.

13. Como puede observarse, el texto convencional aplicable en este ámbito es el Convenio de Viena sobre Relaciones Diplomáticas, al que, además, remite expresamente el artículo 27.1 LCJI. Esta remisión al Convenio de Viena -que, en esencia, regula las funciones de las misiones diplomáticas-, entiendo que, para el particular contexto de notificaciones a Estados extranjeros demandados ante tribunales españoles, se concreta en el artículo 41.2) del mismo ${ }^{13}$. En su virtud, el órgano judicial debe notificar al Ministerio de Asuntos Exteriores para que sea éste quien -mediante nota verbal- notifique a la Embajada del Estado demandado sita en España. Repárese, sin embargo, que el cauce así descrito es distinto al cauce previsto en el artículo 54 LOPI (comunicaciones entre el Ministerio de Asuntos Exteriores y los órganos judiciales españoles). En efecto, el artículo 54 LOPI -cuyo título no refleja con precisión el supuesto que regula- prevé que el Ministerio de Asuntos Exteriores remita la notificación a la misión diplomática española en el Estado extranjero demandado, para que sea esa misión diplomática la que, a su vez, remita la notificación al Ministerio de Asuntos Exteriores de ese Estado. Es decir, mientras que el artículo 27.1 LCJI prevé -mediante remisión al Convenio de Viena sobre Relaciones Diplomáticas- que la comunicación se haga a la Embajada extranjera en España, el artículo 54 LOPI, por su parte, prevé que esa comunicación se haga a la Embajada española en el Estado extranjero.

La Asesoría Jurídica del Ministerio de Asuntos Exteriores español [AJI] afirma que: "11.- El régimen previsto en el artículo 54 de la Ley Orgánica de Inmunidades se encuentra en plena armonía con la Ley de CJIMC, con el mandato de la Convención de Viena de 1961 y con la Convención de Nueva York de 2004, en cuyo artículo 22.1.c se establece el mismo sistema que previó nuestro Legislador en la LO de Inmunidades y la Ley de CJMI de 2015, cuatro años después de que el Reino de España se hubiera adherido a la citada Convención de Nueva York"14.

14. Ante este complejo marco normativo debe determinarse entonces si existe algún tipo de jerarquía entre los cauces descritos o si, por el contrario, ambos pueden invocarse indistintamente. Pues bien, a mi juicio, la respuesta a la cuestión así suscitada debe resolverse del siguiente modo: debe prevalecer, en principio, el cauce previsto en el convenio internacional en vigor que regula esta cuestión (al que, además, remite expresamente el artículo 27.1 LCJI) sobre el cauce previsto en el artículo 54 LOPI. De tal forma que solo en aquellos supuestos en los que, a la luz de las circunstancias, no pudiera seguirse el cauce previsto en el texto internacional, entraría en juego el cauce previsto en el artículo 54 LOPI. Esta interpretación estaría, además, en línea con la ratio del mismo artículo 54 LOPI. Repárese en que el citado precepto se inspira en el artículo 22 de la Convención NU sobre las Inmunidades Jurisdiccionales de los Estados y de sus Bienes (no en vigor) ${ }^{15}$; precepto que diseña un cauce de transmisión por vía diplomática con el Ministerio de Relaciones Exteriores del Estado interesado muy similar al previsto en el artículo 54 LOPJ. Ahora bien, como explicita el mismo precepto, el cauce descrito es de aplicación subsidiaria "a cualquier convenio internacional aplicable" o "cualquier arreglo especial de

${ }^{13}$ Y no al artículo 27 del texto convencional, como he destacado en otra sede. Vid., M. Gómez Jene, "Artículo 27. Emplazamientos y comunicaciones judiciales dirigidos a Estados extranjeros", en: M MÉndez González / G. Palao Moreno (Dirs.), Comentarios a la Ley de cooperación jurídica internacional en materia civil, Tirant lo Blanch, Valencia, 2017, pp. 350-360.

${ }^{14}$ Informe AJI de 15 de junio de 2021, No: 22438 CJB/MBP (inédita).

15 No en vigor, aunque España está adherido al mismo. 
notificación entre el demandante"; es decir, reconoce la aplicación de cualquier otro convenio internacional aplicable: en nuestro particular contexto, el Convenio de Viena sobre Relaciones Diplomáticas. En consecuencia, el cauce inicialmente aplicable para notificar a un Estado extranjero demandado ante un tribunal español es el cauce previsto en el citado Convenio de Viena.

15. En cualquier caso, a la luz de las circunstancias del supuesto concreto (ad ex. no ratificación del Convenio por el Estado al que deba notificarse, falta de representación diplomática en España), incluso podría defenderse la aplicación alternativa de las normas citadas, siguiendo un simple criterio de eficacia: se trataría de aplicar aquella norma que garantizase la notificación de la forma más rápida posible sin poner en riesgo ni la inmunidad soberana ni los derechos de defensa del Estado afectado. Así visto, ningún inconveniente debe plantear el hecho de que una notificación se tramite por el cauce del artículo 54 LOPI en vez de por el cauce previsto en el Convenio de Viena: ambas vías garantizan perfectamente tanto la inmunidad soberana del Estado afectado (evitando cualquier comunicación directa entre tribunales del foro y la misión diplomática) como los derechos de defensa del Estado demandado.

16. Lo que, en cualquier caso es evidente es que el hecho de que se utilice un cauce u otro (no se utiliza el cauce del Convenio porque el Estado no tiene embajada en España) no supone una vulneración alguna de una norma esencial del procedimiento que justifique, por ejemplo, una nulidad de actuaciones. $\mathrm{Y}$ desde esta perspectiva, la escasa jurisprudencia de los tribunales españoles demuestra cierta confusión al respecto, llegando incluso a deducir del marco legal aplicable unas conclusiones desorbitadas. Así, el TSJ de Madrid ha apreciado una nulidad de actuaciones porque el MAEX utilizó en su momento el cauce del Convenio de Viena frente al cauce previsto en el artículo 54 LOPI para notificar a un Estado extranjero ${ }^{16}$.

\section{A modo de conclusión}

17. El cauce para librar la notificación a un Estado extranjero demandado ante un tribunal español, aun siendo complejo, debería aplicarse del siguiente modo:

En primer lugar debe tenerse en cuenta la posible aplicación del Reglamento de notificaciones refundido (supuestos intraeuropeos).

En defecto de aplicación del Reglamento (básicamente, supuestos extraeuropeos) es de aplicación, en principio, el cauce previsto en el artículo 41.2 del Convenio de Viena sobre Relaciones Diplomáticas antes que el cauce previsto en el artículo 54 LOPI.

No obstante lo anterior y a la luz de las circunstancias (existencia o no de misiones diplomáticas), la aplicación del artículo 54 LOPI también puede considerarse, pues tanto el cauce previsto en el Convenio de Viena como el cauce previsto en este último precepto preservan igualmente tanto la inmunidad soberana del Estado afectado como sus derechos de defensa. Asumiendo el respeto a ambas cuestiones, el hecho de que el Ministerio de Asuntos Exteriores utilice un cauce y no otro no debe tener consecuencia alguna en el contexto del procedimiento abierto contra el Estado extranjero: ambos cauces respetan por completo tanto la inmunidad de jurisdicción como los derechos de defensa de dicho Estado.

Declarar una nulidad de actuaciones -como ha hecho el TSJ de Madrid- dos años después de haberse dictado la resolución que está en el origen del incidente de nulidad (i) porque el MAEX utilizó el cauce previsto en el Convenio de Viena y no el cauce previsto en el artículo 54 LOPI es incomprensible: ambos cauces respetan plenamente las garantías del Estado demandado.

${ }^{16}$ Auto TSJ de Madrid, 29 junio 2021, Juicio Verbal (250.2) 4/2018. El auto, no obstante, contiene un acertado y estudiado voto particular cuyo sentido comparto plenamente. 